\title{
Direction of injection does not affect the spread of spinal bupivacaine in parturients
}

Édith Massé MD,

Pierre Drolet MD FRCPC, Michel Girard MD MHPE FRCPC

Purpose: One of the factors that can affect the distribution of local anaesthetic solutions in the subarachnoid space is the direction of the spinal needle through which injections are made. This study investigated the effect of the direction of the aperture of the Whitacre needle on the spread of hyperbaric bupivacaine in parturients undergoing elective caesarean section.

Methods: Forty healthy term parturients scheduled for caesarean delivery under spinal anaesthesia with $12 \mathrm{mg}$ hyperbaric bupivacaine $+0.2 \mathrm{mg}$ morphine were randomly assigned to one of two groups: needle orifice cephalad (I) or caudad (II). Spinal blocks were administered in the sitting position with patients being positioned supine immediately after. A blinded observer assessed the dematome level of analgesia to ice every minute for the first 10 minutes, every three minutes for the following $35 \mathrm{~min}$, then every $15 \mathrm{~min}$ until the sensory level regressed to $T_{10}$.

Results: There was no difference between the groups regarding the maximal number of segments blocked cephalad to $T_{11}(11.4 \pm 3.4$ : group I and $12.0 \pm 3.4$ : group II), time to highest cephalad spread of sensory block (22 \pm 10: group I and 19 \pm 10 min: group II), or time to regression to $T_{10}(164 \pm 26:$ group I and I $53 \pm 24$ min: group II). The maximum decrease in blood pressure (33.9 $\pm 9.6:$ group I and $36.8 \pm 11.8 \mathrm{mmHg}$ : group II) and dosage of ephedrine administered (14.7 \pm 10.7 : group I and $16.2 \pm 11.0 \mathrm{mg}$ : group II) did not differ.

Conclusion: The direction of the aperture of the Whitacre needle does not influence the spread of hyperbaric bupivacaine in the term parturient.

Objectif : La direction de l'aiguille constitue un des facteurs influençant la distribution sous-arachnoïdienne des anesthésiques locaux. Cette étude visait à examiner l'influence de la direction de l'orifice de l'aiguille Whitacre sur la diffusion d'une solution hyperbare de bupivacaïne administrée pour une césarienne non urgente.

Méthodes : Quarante parturientes à terme et en bonne santé programmées pour une césarienne sous rachianesthésie réalisée avec $12 \mathrm{mg}$ de bupivacaïne hyperbare et $0,2 \mathrm{mg}$ de morphine ont été assignées aléatoirement à un des deux groupes : orifice de l'aiguille en direction céphalique (I) ou caudale (II). La rachianesthésie était administrée en position assise et la patiente était placée immédiatement sur le dos. Un observateur neutre évaluluait à l'aide d'un glaçon le niveau de l'anesthésie à la minute pour dix minutes, aux trois minutes pour les 35 min suivantes et aux quinze minutes jusqu'à la régression à $D_{10}$ du niveau sensoriel.

Résultats : II riy a pas eu de différence entre les groupes en ce qui concerne le nombre de segments bloqués en direction céphalique par rapport à $D_{1 \mid}$ (groupe $1: 11,4 \pm 3,4$ et groupe $11: 12,0 \pm 3,4$ ). le temps d'installation du bloc sensitif à son plus haut niveau céphalique (groupe $1: 22 \pm 10 \mathrm{~min}$ et groupe $11: 19 \pm 10 \mathrm{~min}$ ), ou le temps de régression à $D_{10}$ (groupe $1: 164 \pm 26 \mathrm{~min}$ et groupe $11: 153 \pm 24 \mathrm{~min}$ ). La baisse maximale de la pression artérielle (groupe 1: $33.9 \pm 9,6 \mathrm{mmHg}$ et groupe $11: 36,8 \pm 11,8 \mathrm{mmHg}$ ) et la dose d'éphédrine administrée (groupe 1:14.7 $\pm 10,7 \mathrm{mg}$ et groupe $11: 16,2 \pm 11,0 \mathrm{mg}$ ) étaient identiques.

Conclusion : La direction de l'onfice de l'aiguille Whitacre n'influence pas la diffusion de la bupivacaïne hyperbare chez la parturiente à terme.

From the Department of Anaesthesia, Maisonneuve-Rosemont Hospital, University of Montréal, 5415 l'Assomption Blvd, Montréal, Québec, Canada HIT 2M4.

Address correspondence to: Dr. Picrre Drolet.

Accepted for publication May Q, 1997. 
S UBARACHNOID injection is an established method of providing anaesthesia for patients undergoing caesarean section. ${ }^{1}$ Pencil point needles of smaller calibre are responsible for the growing popularity of this technique since they permit a reduction in the incidence of postdural puncture headache. ${ }^{2}$ Still, variables capable of influencing the spread of sensory blockade following injection of local anaesthetic in the term parturient are not well defined. Among these, it has been suggested that the direction of the spinal needle aperture may be important. ${ }^{3,4}$

The present double-blind trial was undertaken to determine if the direction of the aperture of the Whitacre needle affects the spread of hyperbaric bupivacaine in parturients undergoing elective caesarean section.

\section{Methods}

After receiving approval from our institutional review board, we obtained written consent from 40 healthy nonlabouring term parturients scheduled for caesarean section under spinal anaesthesia. Patients were randomly allocated to one of two groups $(n=20)$ : (I) needle orifice cephalad, or (II) needle orifice caudad. In each patient, the blood pressure (automated cycling device, Datex Instrumentarium Corp., Helsinki, Finland), heart rate and ECG were monitored throughout the study. Lactated Ringer's solution, $20 \mathrm{ml} \cdot \mathrm{kg}^{-1}$, was infused iv as quickly as possible before placing each parturient on the operating table in the sitting position. Using a midline approach, a 27-gauge Whitacre spinal needle was inserted into the subarachnoid space at the $\mathrm{L}_{3}-\mathrm{L}_{4}$ interspace. After obtaining free flow of cerebrospinal fluid, $12 \mathrm{mg}$ bupivacaine $0.75 \%$ in dextrose $8.25 \%$ (Marcaine, Sanofi Winthrop, Markham, Ontario) $+0.2 \mathrm{mg}$ preservative free morphine $0.05 \%$ were injected over $10 \mathrm{sec}$ with the needle aperture oriented according to the study group. Immediately, each patient was positioned supine with a wedge placed under her right hip to provide left uterine displacement. The operating table remained horizontal throughout the surgery.

Systolic blood pressure values and dermatome levels of sensory analgesia to ice were recorded by an observer, blinded to the direction of the needle aperture, every minute for the first $\mathbf{1 0} \mathrm{min}$ after anaesthetic injection, every three minutes for the following 35 min, then every 15 min thereafter. Ephedrine (5-10 $\mathrm{mg}$ ) $i v$ was administered if the systolic blood pressure reached $100 \mathrm{mmHg}$ or decreased by $20 \%$ or more compared with the value recorded just before subarachnoid injection (time 0). Motor blockade was assessed with the Bromage scale (Table I) on arrival of the patient in the recovery room and every $15 \mathrm{~min}$ thereafter. Insufficient analgesia and nausea were treated respectively with $25-50 \mu \mathrm{g}$ fentanyl $i p$ and 10 mg metoclopramide $i v$. The study period ended when the sensory blockade regressed to $T_{10}$.

Unpaired $t$ tests were used to compare demographic data, maximal number of segments blocked, time to highest cephalad spread, time to regression to $T_{10}$ and largest decrease in blood pressure. One way ANOVA was used to compare systolic blood pressure and number of segments blocked between groups for each interval. The Mann-Whitney U test was used to compare intensity of motor blockade between the groups for each interval. Results are expressed as mean \pm SD. $P<0.05$ was considered statistically significant.

\section{Results}

The two groups did not differ in age, weight, height and blood pressure just before the injection (Table II). There was no difference with regard to the maximal number of segments blocked cephalad to $T_{11}(11.4 \pm$ 3.4: group I and $12.0 \pm 3.4$ : group II), time to highest cephalad spread $(22 \pm 10$ : group I and $19 \pm 10$ min: group II), or time to regression to $\mathrm{T}_{10}(164 \pm 26$ : group I and $153 \pm 24$ min: group II) (Table III). The

TABLE I Bromage scale for motor blockade

\begin{tabular}{ll}
\hline 4 & Full flexion of knees and feet \\
3 & Just able to flex knees, full flexion of feet still possible \\
2 & Unable to flex knees, full flexion of feet possible \\
1 & Unable to move legs or feet \\
\hline
\end{tabular}

TABLE II Demographic data

\begin{tabular}{llll}
\hline Group & $I(n=20)$ & $I I(n=20)$ & $P$ \\
\hline Age $(\mathrm{yr})$ & $29 \pm 5$ & $28 \pm 5$ & NS \\
Weight $(\mathrm{kg})$ & $87 \pm 21$ & $81 \pm 14$ & NS \\
Height $(\mathrm{cm})$ & $161 \pm 6$ & $159 \pm 6$ & NS \\
$\begin{array}{l}\text { Systolic blood pressure } \\
\quad(\mathrm{mmHg})^{\star}\end{array}$ & $131 \pm 15$ & $131 \pm 12$ & NS \\
\hline
\end{tabular}

*Before spinal injection

Mean \pm SD

TABLE III Sensory blockade

\begin{tabular}{llll}
\hline Group & $I(n=20)$ & $I I(n=20)$ & $P$ \\
\hline $\begin{array}{llll}\text { Number of segments blocked } \\
\left.\quad \text { (cephalad to } \mathrm{T}_{11}\right)\end{array}$ & $11.4 \pm 3.4$ & $12.0 \pm 3.4$ & NS \\
Time to highest block $(\mathrm{min})$ & $22 \pm 10$ & $19 \pm 10$ & $\mathrm{NS}$ \\
Time to regression to $\mathrm{T}_{10}(\mathrm{~min})$ & $164 \pm 26$ & $153 \pm 24$ & $\mathrm{NS}$ \\
\hline
\end{tabular}

Mean \pm SD 
groups did not differ in the number of segments blocked at each interval (Figure 1).

The largest decrease in blood pressure $(33.9 \pm 9.6$ : group I and $36.8 \pm 11.8 \mathrm{mmHg}$ : group II) and dosage of ephedrine administered (14.7 \pm 10.7: group I and $16.2 \pm 11.0 \mathrm{mg}$ : group II) did not differ. There was no difference between the groups either with regard to the systolic blood pressure for each interval (Figure 2).

There was no difference with regard to motor blockade intensity between groups for each interval (Table IV). Five patients (three in group I and two in group II) received one dose of fentanyl during surgery. Seven patients in each group received metoclopramide during the study period. Two patients, both belonging to group II, were given $\mathrm{N}_{2} \mathrm{O}$ by mask toward the end of surgery. None of those differences was significant.

\section{Discussion}

At least 25 factors have been advocated as determinants of the spread of local anaesthetic solutions in cerebrospinal fluid. ${ }^{5-9}$ Though hypothetical, many are often cited nonetheless. One of the major problems in determining the influence of one factor is to control the others effectively. It also makes it difficult to compare studies since small variations in methods are almost unavoidable. The present study found no relation between the time to onset or regression of sensory blockade, its extent, or variations in blood pressure and the direction of the Whitacre needle aperture in the term parturient.

There are two mechanisms by which "directional spinal analgesia" could be achieved by variation in the needle insertion technique: first, the direction in which the local anaesthetic goes might be influenced by the angle between the longitudinal axis of the subarachnoid space and the axis of a regular (Quincke) needle and second, the direction (caudad or cephalad) of the orifice of a side lumen needle. The first alternative was explored by Stienstra who concluded, after studying 40 patients, that a steep paramedian approach of the subarachnoid space with an angle of $<50^{\circ}$ resulted in a cephalad spread averaging $1.6 \mathrm{seg}$ ments greater than when the Quincke needle was in the perpendicular position. ${ }^{10}$ This is at variance with our results although a variety of factors may explain this difference besides the needle type. All patients studied by Stienstra were male, making comparison between the two studies difficult since spinal anaesthesia in obstetrics differs from its counterpart in the non-pregnant patient. ${ }^{1}$ Baricity of the anaesthetic solutions injected was also different since $15 \mathrm{mg}$ plain bupivacaine $0.5 \%$, a slightly hypobaric solution, was used by Stienstra. Finally, Stienstra's patients were kept sitting three minutes after injection while patients in our study were positioned supine immediately. Two authors have studied the influence of direction of the aperture of Whitacre needles on the extension of sensory blockade. ${ }^{3,4}$ Both concluded that cephalad orien-

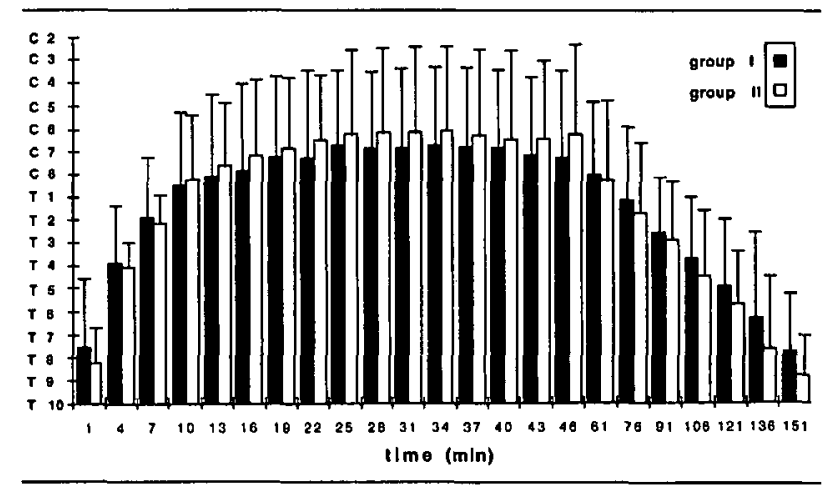

FIGURE 1 Extent of the sensory blockade $v$ time after injection. Mean \pm SD (ANOVA, NS)

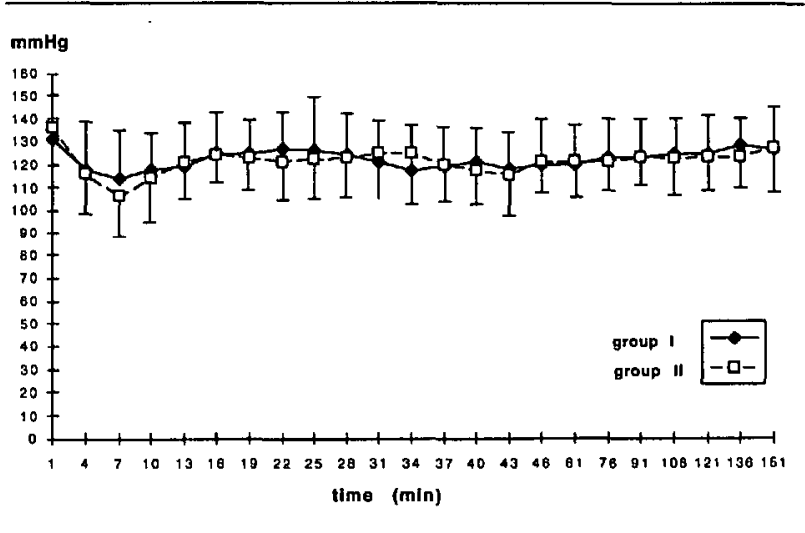

FIGURE 2 Systolic blood pressure vs time after injection. Mean \pm SD (ANOVA, NS)

TABLE IV Motor blockade in the recovery room (Bromage scale $1-4$ )

\begin{tabular}{lllllll}
\hline $\begin{array}{c}\text { min after } \\
\text { spinal injection }\end{array}$ & $75-89$ & $90-104$ & $105-119$ & $120-134$ & $135-149$ & $150-164$ \\
\hline $\begin{array}{c}\text { Bromage } \\
\text { scale }\end{array}$ & & & & & & \\
1 & $14 / 18$ & $13 / 15$ & $5 / 8$ & $3 / 3$ & $2 / 2$ & $1 / 1$ \\
2 & $2 / 1$ & $3 / 2$ & $8 / 5$ & $6 / 7$ & $1 / 4$ & $1 / 2$ \\
3 & $2 / 0$ & $2 / 2$ & $3 / 3$ & $4 / 5$ & $5 / 7$ & $4 / 5$ \\
4 & $0 / 1$ & $0 / 0$ & $2 / 4$ & $3 / 2$ & $4 / 2$ & $3 / 3$ \\
\hline
\end{tabular}

$n$ group $\mathrm{I} / \mathrm{n}$ group II

All differences between groups for each interval are NS with Mann-Whitney "U" test 
tation was associated with higher spread of the anaesthetic solution when compared with caudad orientation. First, Neigh et al. noted that cephalad injection of a height adjusted dose of hyperbaric tetracaine through a Whitacre needle produced higher levels than caudad injection. He also noted that the range of variability was so wide that results were largely unpredictable for an individual patient. Again, the population studied by the author did not include any patient undergoing caesarean section. Graham et al. showed that caudad injection of $7 \mathrm{mg}$ hyperbaric amethocaine with adrenaline 1:100,000 via a 22-gauge Whitacre needle was inadequate for elective caesarean section, while cephalad or lateral injection provided good sensory levels for the duration of surgery. In that study, spinal blocks were administered in the lateral position and each group included only seven patients.

An interesting finding was the lengthy period that we observed before the spread of the anaesthetic solution was complete. Norris suggested ${ }^{11,12}$ that, according to unpublished data, the maximum level of sensory blockade occurred by 10-12 min. Since it took longer in our participants $(22 \pm 10$ in group I and $19 \pm 10 \mathrm{~min}$ in group II), we suggest that patients should be observed for at least $30 \mathrm{~min}$ following injection of hyperbaric solution before it is concluded that the sensory level is stable.

In conclusion, the direction of the aperture of the Whitacre needle does not influence the cephalad spread of hyperbaric bupivacaine in the term parturient.

\section{Acknowledgment}

The authors thank $C$. Coté for her assistance with the data collection.

\section{References}

1 Kestin IG. Spinal anaesthesia in obstetrics. $\mathrm{Br} \mathrm{J}$ Anaesth 1991; 66: 596-607.

2 Halpern S, Preston R. Postdural puncture headache and spinal needle design. Metaanalyses. Anesthesiology 1994; 81: 1376-83.

3 Graham CW, Sutton L, Cozen HJ. Directional spinals in obstetric analgesia. Anaesthesia 1978; 33: 192-5.

4 Neigh JL, Kane PB, Smith TC. Effects of speed and direction of injection on the level and duration of spinal anesthesia. Anesth Analg 1970; 49: 912-8.

5 Greene NM. Distribution of local anesthetic solutions whitin the subarachnoid space. Anesth Analg 1985; 64: 715-30.

6 Hartwell BL, Aglio LS, Hauch MA, Datta S. Vertebral column length and spread of hyperbaric subarachnoid bupivacaine in the term parturient. Reg Anesth 1991; 16: 17-9.
7 Lowson SM, Brown J, Wilkins CJ. Influence of the lumbar interspace chosen for injection on the spread of hyperbaric $0.5 \%$ bupivacaine. Br J Anaesth 1991; 66 : 465-8.

8 Inglis $A$, Daniel $M, M c G r a d y$ E. Maternal position during induction of spinal anacsthesia for Caesarean section. Anaesthesia 1995; 50: 363-5.

9 De Simone CA, Leighton BL, Norris MC. Spinal anesthesia for cesarean delivery. A comparison of two doses of hyperbaric bupivacaine. Reg Anesth 1995; 20: 90-4.

10 Stienstra $R$, van Poorten $F$, Kroon JW. Needle direction affects the sensory level of spinal anesthesia. Anesth Analg 1989; 68: 497-500.

11 Norris MC. Height, weight, and the spread of subarachnoid hyperbaric bupivacaine in the term parturient. Anesth Analg 1988; 67: 555-8.

12 Norris $M C$. Patient variables and the subarachnoid spread of hyperbaric bupivacaine in the term parturient. Anesthesiology 1990; 72: 478-82. 